\title{
Editora Conexão 7: trajetória em perspectiva de ideologia étnica, produção de literatura e crise em modelos de negócio
}

\author{
Hudson Mina \\ Biólogo - UNISUAM \\ Especialista em Ensino de Ciências - UERJ \\ Professor da Rede Pública Municipal do Rio de Janeiro \\ Diretor de Arte (Editora Conexão 7) \\ editora.conexao7@uol.com.br
}

A Editora Conexão 7 (EC7) surgiu de uma necessidade do professor e escritor, Percio Mina, em tornar possível a visibilidade não apenas de seus livros, mas também das obras de outros autores, principalmente, os que passam por dificuldades para ingressar no universo literário, semelhantes às que ele vivenciou.

Trata-se de uma empresa familiar, constituída por três irmãos negros, professores (Percio, Hudson e Priscilla Mina) que têm a educação como um forte objetivo em comum. Além disso, foi percebido uma inquietude convergente, apontando uma necessidade de luta por reparação nas questões étnico-sociais, as quais se tornariam o ponto de partida para a inauguração da Editora no mês de julho, ano de 2017.

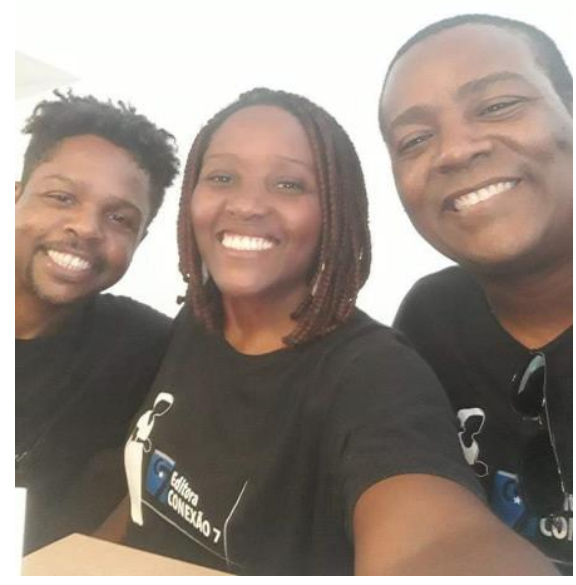

Editores da EC7, da esquerda para a direita: Hudson Mina, Priscilla Mina e Percio Mina. 
A proposta de criar a empresa com a filosofia voltada às ações afirmativas em prol do Negro, partiu do Percio Mina, nos levando a acreditar na viabilidade do nosso envolvimento e comprometimento nesse projeto. Contudo, a EC7 preconiza um trabalho voltado para o lançamento de livros de novos autores, dando um auxílio na divulgação de sua marca de escritor no mercado, independentemente de sua etnia ou crença. É importante ressaltar que temos um setor responsável pela análise dos textos, pois precisam estar em consonância com valores que não tenham um caráter ofensivo, mesmo o autor tendo a total responsabilidade por sua obra.

Embora estejamos no mercado há 3 anos, publicamos cerca de 50 títulos, dentre eles "O Batom Vermelho" e "Eu Sei - As Histórias Que Mais Ninguém Sabe", ambos de autoria de Percio Mina. $O$ primeiro constrói 14 contos consubstanciados em uma linguagem juvenil. Já o segundo, aborda a narrativa do filho do mestre Cartola da Mangueira, Ronaldo Silva de Oliveira, que revela passagens da vida familiar, relações e conflitos afetivos entre pai e filho, ou seja, uma dinâmica que distancia a imagem do ícone da música popular brasileira, dando vez ao homem, pai e marido. 0 Percio Mina teve outras iniciativas ao escrever dois romances anteriormente: "O Pracinha Brasileiro" e o "Fruto da terra seca".

Priscilla Mina é responsável pelo desenvolvimento operacional e administrativo, assumindo a função de presidir a empresa numa configuração de competência, sobretudo, de representatividade no universo feminino, principalmente, da "Mulher Preta". É organizadora do Projeto Identidade, cuja primeira edição foi em 2018, dando visibilidade a 18 mulheres negras, por meio do livro de poesias "Alma", uma antologia significativa, até mesmo pelo local de lançamento que foi no Museu do Negro, localizado no Centro do Rio de Janeiro ("Hoje fechado por motivo de força maior"). Esse projeto ganhou sequência nesse ano, tendo aspecto de tradição, através de antologia escrita por 18 autoras negras. Desta vez, evidenciam-se narrativas, que dão forma ao livro "Vozes da Resistência", o qual tem o mesmo poder do anterior: Descortinar a Força e a Alma de mulheres pretas. Vale salientar, que o lançamento dessa obra foi de forma virtual, por conta da pandemia pelo novo Coronavírus.

Os nossos lançamentos ocorrem de forma presencial, com a contribuição de parceiros cedendo seus espaços físicos, geralmente comerciais, importantes para a efetividade de nossa empresa, apesar da EC7 usar a internet como grande aliada na sua infraestrutura (Plataformas de vendas e informações). 
É fundamental ratificar que somos uma empresa virtual, com "espinha dorsal" humanizada, que permite um envolvimento físico em nosso trabalho. Haja vista o nosso modelo de lançamento, como por exemplo, os lançamentos de dois livros na Universidade Estadual do Rio de Janeiro (UERJ): O "Rio de Janeiro Inusitado" e o "Zoo in Rio: Uma história da fauna carioca, do Brasil Colonial ao Estado Novo". Ambos de autoria do professor Francisco J. Figueiredo, doutor em Ciências Biológicas e pesquisador do Departamento de Zoologia (DZ), do Instituto de Biologia Roberto Alcantara Gomes (IBRAG/UERJ), cuja abordagem traz um prisma comum relacionando-se ao Rio de Janeiro em contextos históricos. Então, para o primeiro livro foi utilizado o Centro Cultural (COART) e o segundo, ocorreu na Capela Ecumênica, com a participação de outros autores, Valéria Gallo e Bruno Absolon, também professores e pesquisadores (DZ/IBRAG).

O Percio Mina não atua somente como escritor, pois dirige o Setor de Relacionamento, junto aos autores ou parceiros, exercendo também a função de Editor-Chefe. Por conseguinte, minha atuação é dirigir o Setor de Arte, onde me responsabilizo pela criação das ilustrações ou imagens, desde a concepção das capas dos livros até a identidade da empresa, aproveitando para dar crédito a designer Isabelle Reis, que contribui muito ao sucesso da nossa produtividade. No entando, tenho outra atribuição relacionada à produção de atividades culturais que possam dar protagonismo a pessoas negras, como por exemplo, o seminário "Cultura Negra Para A Escola" e o Fórum Literário EC7, eventos emblemáticos realizados na UERJ. Esses eventos foram coordenados por mim, mas só aconteceram de fato devido a participação não somente dos convidados e palestrantes, como também pela parceria com o Professor e Coordenador do Curso de Especialização em Ensino de Ciências (DECB/IBRAG), Waisenhowerk Melo.

O Fórum Literário EC7, que ocorreu em setembro de 2019 na UERJ, recebe o enfoque pela participação de profissionais que ganharam notoriedade na "Literatura Preta", isto é, Eliana Alves Cruz, autora dos livros “Água de Barrela" e "O Crime do Cais do Valongo" (Editora Malê) e Anielle Franco, autora e organizadora do livro "Cartas para Marielle" (EC7).

A obra "Cartas para Marielle" foi publicada pela Editora Conexão 7, trazendo à tona um pouco do sentimento dos pais, da filha e da irmã da vereadora Marielle Franco (PSOL-RJ), em decorrência do trágico e estarrecedor "14 de março de 2018", dia de sua morte. Esse livro é muito importante para os membros da EC7, por conta do nosso carinho, admiração e 
amizade pela família Franco. Portanto, foi significativo o lançamento do livro na Feira Literária de Paraty (FLIP/2019) e no Instituto Marielle Franco.

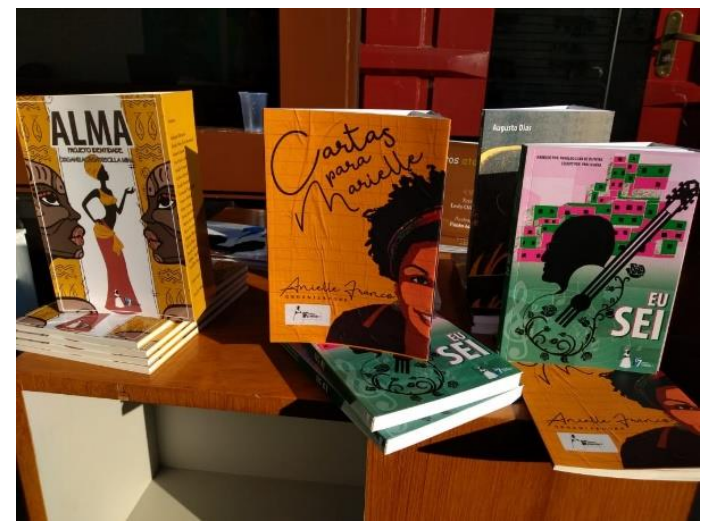

Feira Literária de Paraty (FLIP/2019).

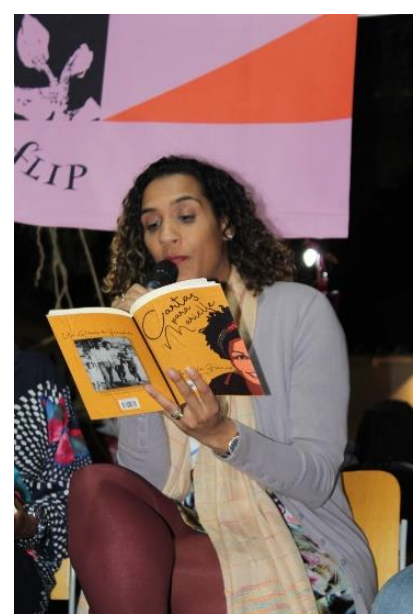

Escritora Anielle Franco em leitura na FLIP (2019).

A Editora teve uma breve passagem pela Rádio Mundial News FM (Web tv, com a direção de Paulo Roberto Accioli) de 2018 a 2019, onde foi criado o programa "Conexão 7 No Ar".

O programa de cunho informativo, sob uma ótica descontraída, que deu oportunidade a profissionais de áreas diversificadas (Arte, Saúde, Jornalismo etc.) divulgarem seus trabalhos. Também visava o potencial da negritude, tendo a honra da participação da vereadora Marielle Franco em uma de suas edições, na qual discorreu sobre questões de extrema relevância no âmbito social. Recordo-me do momento em que mencionei uma preocupação, como também biólogo e professor, sobre um tema recorrente entre os jovens, que é a gravidez precoce na adolescência. $O$ assunto permitiu algumas considerações. A partir da minha vivência no ensino público, ouvi diversos relatos de evasão escolar em detrimento das mães (muito jovens) adquirirem responsabilidades que as levavam a dificuldades no prosseguimento letivo. Neste assunto, a atenção da vereadora, voltou-se principalmente, às condições de meninas da periferia.

Nós entramos no mercado literário num período de turbulência econômica, em que foi noticiado o fechamento de grandes editoras e livrarias. Uma matéria de Gisella Meneguelli (Coluna Viver / Arte e Cultura do site greenme.com.br, publicada em 05/02/2020) nos leva a 
vislumbrar que a falência dessas empresas vai além da crise financeira, diante de um questionamento se brasileiro realmente lê pouco. Ela nos apresenta um cenário dicotômico, onde há leitores que fogem da internet, sob a perspectiva de lerem uma determinada quantidade de livros por ano. Assim, como existe outro perfil de leitores cuja preferência é formar um nicho de consumo através de clubes de leituras pelas redes sociais, além do crescimento comercial das plataformas virtuais.

As plataformas virtuais entram no mercado e assumem uma grande fatia na disputa pelo "bolo literário", em um momento que as megastores enfrentam dificuldades em seus modelos de negócio. Dentro desse contexto, a matéria do site "greenMe", ainda nos revela uma reportagem do Jornal "El Pais", que apresenta um percentual de $25 \%$ na redução do mercado editorial brasileiro a partir de 2006, mas em contrapartida surge o "Clube de Autores", que obteve um aumento de 30\% no seu faturamento em 2018. É “a maior plataforma de autopublicação da América Latina", com elevados atendimentos à autores e outros profissionais envolvidos com o mercado editorial.

O mundo não é algo estanque, no que diz respeito aos valores culturais de uma determinada nação. Sobretudo, o Brasil é um país pluralista com grandes potenciais, em particular no setor da literatura, pois há indicadores de públicos que buscam espaço para transformar seus textos em realidade com visibilidade e reconhecimento. Ao mesmo tempo, há brasileiros demonstrando seu gosto por livros, numa quebra de paradigma da máxima em que "brasileiro lê pouco".

A Editora Conexão 7 entra nesse panorama com o objetivo de agregar mão-de-obra e desenvolvimento intelectual, consolidando-se tanto no campo virtual como fisico.

\section{Contatos:}

E-mail: editora.conexao7@gmail.com

Fanpage / Instagram: editoraconexão7

Tel.: (21) 996475296

\section{(cc) EY}

Este trabalho está licenciado com uma Licença Creative Commons - Atribuição 4.0 Internacional. 